\title{
Editorial comments on the special issue of PAWEES 2011 International Conference
}

\author{
Fi-John Chang
}

Received: 13 February 2012/Revised: 20 February 2012/ Accepted: 7 March 2012/Published online: 25 March 2012

(C) Springer-Verlag 2012

It is my pleasure and great honor as the organizer of "PAWEES 2011 International Conference" held at National Taiwan University (NTU) in Taiwan on October 27,2011 . The conference objective was to make a platform for researchers and scientists to share and present new advances, research results, perspectives and experiences in Paddy and Water Environment and related areas. Special attentions were given to developing certain skills or competence, or general upgrading of performance ability for participatory irrigation and environmental management. The conference brought together leading researchers, engineers, and scientists in the domain of interest from around the world.

The theme of the conference was "Capacity Building for Participatory Irrigation and Environmental Management". Four topics consisted of:

- Paddy Environmental Sustainability and Irrigation Techniques

- Sustainable Water Management

- Impacts of Climate Change and Natural Hazards on Paddy and Water Environment

- River Environmental Design and Restoration

Experts from nine countries have submitted numerous abstracts and/or full papers to PAWEES 2011 International Conference. After peer-review, selected full papers will be published in the special issue of "Paddy and Water Environment".

A series of activities were arranged during PAWEES 2011. The conference was first held at National Taiwan University (NTU), while the 10th PAWEES Annual

F.-J. Chang ( $\square)$

National Taiwan University, Taipei, Taiwan, ROC

e-mail: changfj@ntu.edu.tw
Meeting was next held at the Agriculture Engineering Research Center, Taoyuan. At the end a technical trip was organized to visit the Shihmen Reservoir, one of the most important water resources facilities in northern Taiwan. The Shihmen Reservoir, situated in Taoyuan whose terrain contains plateaus with a dense network of irrigation ponds, is designed for multiple purposes including water supply for irrigation, industrial and domestic uses, flood control, hydropower generation and recreation.

The conference was conducted with great success, which should be fully ascribed to PAWEES, steering committee, conference participants, financial sponsors, and work staffs. The conference could not be held better without your contribution. I in particular appreciate those involved in the preparation for this conference for his/her marvelous endeavors, especially for Professors Ching-Pin Tung and Yu-Pin Lin and Ms Hang-Yeh Lin of NTU for organizing tasks ever since. Special thanks were delivered to the financial sponsors including Taiwan's Water Resources Agency, Council of Agriculture, National Science Council and National Taiwan University.

At the conference, we were delighted to have so many good friends coming from Asia and the United States to attend this conference. Their presence, support and contribution have made this conference truly successful. The audiences gained a lot from their presentations as well. The interactions between the presenters and audiences were not only very intensive but also admirable, which achieved one of the conference goals. Statistics of the conference show that: (1) a total of 208 members from nine countries have participated in this conference; (2) 59 abstracts and 27 full papers were submitted; and (3) thirty-one oral as well as nineteen poster presentations were delivered. The happy banquet was held at the Leader Hotel after the conference. The conference proceedings and album can be downloaded 
from websites of PAWEES (http://pawees.net/) and Taiwan Agricultural Engineers Society (http://www.twaes.org.tw/ PAWEES2011/).

Finally, I highly appreciate for all your great contribution to "PAWEES 2011 International Conference" from the bottom of my heart and wish you all a prosperous year in 2012!! Look forward to seeing you at "PAWEES 2012 International Conference"! 